\title{
Comparison of Intermittent and Bolus Enteral Feeding Methods on Enteral Feeding Intolerance of Patients with Sepsis: A Triple-blind Controlled Trial in Intensive Care Units
}

\author{
Morteza Nasiri ${ }^{1}$, Zahra Farsi ${ }^{2, *}$, Mojtaba Ahangari ${ }^{3}$, Fahimeh Dadgari $^{4}$
}

1. Gastroenterology and Hepatology Disease Research Center, Qom University of Medical Sciences, Qom, Iran

2. Associate Professor, Department of Medical-Surgical, Faculty of Nursing, AJA University of Medical Sciences, Tehran, Iran

3. Department of Critical Care, Faculty of Nursing, AJA University of Medical Sciences, Tehran, Iran

4. Department of Psychiatric, Faculty of Nursing, AJA University of Medical Sciences, Tehran, Iran

\footnotetext{
* Corresponding Author:

Zahra Farsi, Ph.D

Faculty of Nursing, AJA University of Medical Sciences, Kaj St., Shariati St, Tehran, Iran

Telefax: + 987735323012

Email: z.farsi@ajaums.ac.ir;

zahrafarsi@gmail.com
}

Received: 06.Jun. 2017

Accepted: 12 Sep. 2017

\section{ABSTRACT}

\section{BACKGROUND}

Recent trials have shown controversial results on which enteral feeding methods has a lower risk of enteral feeding intolerance. Therefore, we aimed to compare two methods of bolus and intermittent feeding on enteral feeding intolerance of patients with sepsis.

\section{METHODS}

This triple-blind randomized controlled trial was conducted on 60 patients with sepsis, who were fed through tubes for at least 3 days. The patients were randomly assigned into bolus feeding, intermittent feeding, and control groups. Enteral feeding intolerance of all patients was recorded in 3 consecutive days by a researcher-made checklist including the data on gastric residual volume, vomiting, diarrhea, constipation, and abdominal distension.

\section{RESULTS}

There were no significant differences between the three studied groups in none of the intervention days pertaining to constipation, diarrhea, vomiting, abdominal distention, and gastric residual volume $(p>0.05)$. Also, no statistically significant difference was found between all variables in the three studied groups during the 3 days $(p>0.05)$.

\section{CONCLUSION}

As enteral feeding intolerance of patients with sepsis was similar in both bolus and intermittent feeding methods, it can be concluded that bolus method can still be used as a standard method to decrease the risk of enteral feeding intolerance if it is used properly.

KEYWORDS:

Feeding methods, Enteral feeding, Feeding intolerance, Sepsis, Intensive care unit

\section{Please cite this paper as:}

Nasiri M, Farsi Z, Ahangari M, Dadgari F. Comparison of Intermittent and Bolus Enteral Feeding Methods on Enteral Feeding Intolerance of Patients with Sepsis: A Triple-blind Controlled Trial in Intensive Care Units. Middle East J Dig Dis 2017;9:218-227. doi: 10.15171/mejdd.2017.77.

\section{INTRODUCTION}

Nutritional support is considered as essential parts of the management of critically ill patients in the intensive care units (ICUs). ${ }^{1,2}$ Typically, nutritional support of most critically ill hospital inpatients with a functional gastrointestinal tract, who are unable to meet their nutritional needs orally, are provided by enteral feeding (EF) using nasogastric tubes (NGTs). ${ }^{3,4}$ Although EF decrease the mortality of undernourished critically ill patients and has shown promising clinical outcomes, most of the patients fed by tube show symptoms of feeding tube-associated intolerance such as vomiting, diarrhea, constipation, abdominal distention, regurgitation, and high gastric residual volume (GRV). ${ }^{5,6}$

Method of EF has been shown as one of the main factors in the incidence of EF intolerance in critically ill patients. ${ }^{7,8}$ Based on Dietitians Association 
of Australia (DAA), EF can be administered by continuous, intermittent (cyclic/intermittent), and bolus methods based on patients' medical conditions and nutritional requirements. ${ }^{9}$ Most recent trials have compared EF intolerance of continuous feeding with either bolus, ${ }^{10-12}$ or intermittent, ${ }^{13-16}$ feeding methods. Overall, on the basis of the available evidence, researchers have reported controversial results about the risk of EF intolerance by suing any of these methods. Some studies have shown that continuous method in comparison with the bolus or intermittent feeding is associated with better tolerance due to the lower feeding rate, ${ }^{10,12,13}$ while other studies have reported converse results or no differences. ${ }^{11-12,14-16}$

Pertaining to bolus and intermittent methods, most evidence is based on practice and state that intermittent feeding may be better tolerated than bolus feeding, and limited trials have been done in this regard. ${ }^{17,18}$ We hypothesize that there is a difference between EF intolerance of bolus and intermittent methods experienced by tube-fed critically ill patients. According to the abovementioned reason, and as sepsis is common in critically ill patients and because of the paucity of information about EF intolerance of patients with sepsis, ${ }^{19,20}$ we designed this trial to compare the effects of bolus and intermittent EF methods on EF intolerance of hospital inpatients with sepsis admitted to ICU.

\section{MATERIALS AND METHODS}

\section{Study design and ethical consideration}

This was a randomized, controlled, triple blind, three arm clinical trial (code No. IRCT2015102623446N2). The trial was approved by the Ethics Committee of AJA University of Medical Sciences, Tehran, Iran (code No. IR.AJAUMS.REC.38.1394). The study followed the declarations of Helsinki and all ethical principles were considered. After assurance of confidentiality and anonymity and verbal explanations about the study details, the researchers obtained a written informed consent from the patients' family members. The researchers ensured all the patients' family members that participation of the patients in the study is voluntary and they had the right to discontinue the study at any time, without any deprivation from routine treatments.

\section{Samples}

This study was conducted on patients with sepsis who had admitted to ICUs of Shahid Chamran Hospital, Tehran, Iran, from October 2015 to September 2016. All hospital inpatients admitted to the ICUs with the diagnosis of sepsis confirmed by critical care medicine fellowships were recruited. The inclusion criteria were:

1) age of 18-65 years;

2) score of level of consciousness less than 10;

3 ) inability to swallow food orally and having indications for NGT feeding;

4) having indications for both bolus or intermittent feeding methods;

5) having healthy digestive system, which was confirmed by critical care medicine fellowships;

6) lack of fistula, necrosis, obstruction, and surgery of gastrointestinal system,

7) lack of peritonitis; and

8) lack of any history of addiction, cigarette, and alcohol abuse.

The exclusion criteria were:

1) development of ability to eat orally during the study;

2) increasing level of consciousness from the baseline;

3) discharge from ICU before 10 days of hospital admission;

4) development of hemodynamic instability;

5) need for urgent diagnostic or therapeutic procedures;

6) presence of any signs of dehydration or addiction;

7) need for changing diet or prescribing a specific diet during the study.

Based on an earlier study, ${ }^{21}$ using clinical trial formula with the confidence level of $95 \%$ and a power of 0.90 , the number of needed samples was calculated as 17 subjects. For getting more confident results with a $20 \%$ dropout rate, we considered 20 patients in each group. The patients were selected initially through convenient sampling methods and then those who met the inclusion criteria were randomly allocated to three groups of bolus feeding $(n=20)$, intermittent feeding $(n=20)$ and control $(n=20)$ by the first masked researcher assistant using sealed envelope technique and computer generated random numbers.

\section{Outcome Measures}

Demographic and clinical characteristics of the patients 
were recorded using a researcher-made checklist (including age, sex, weight, and duration of hospital admission) at the beginning of the study by an ICU nursing staff (second researcher assistant).

For evaluating EF intolerance of the patients a researcher-made checklist was used including data on constipation, diarrhea, vomiting, abdominal distension, and GRV. In bolus feeding, GRV was assessed by gastric aspiration every three hours after feeding. If aspirated volume was more than $200 \mathrm{cc}$, then $100 \mathrm{cc}$ of the aspirated content was replaced along with the rest of the feeding amount and aspiration was rechecked after $3 \mathrm{~h}$. In intermittent feeding, GRV was assessed every four hours after stopping the feeding pump for half an hour and aspiration of gastric contents. If aspirated volume was more than $200 \mathrm{cc}$ then $100 \mathrm{cc}$ of the aspirated content was replaced, feeding was continued at same rate for next 4 $\mathrm{h}$ and aspiration was rechecked. If aspiration was still more than $200 \mathrm{cc}$, sign of intolerance was confirmed. ${ }^{22}$ All variables were evaluated as absent (score 0) or present (score 1), except GRV that was assessed as less (score 0) or more (score 1) than $200 \mathrm{cc}$. The scientific validity of the researcher-made checklist was obtained using content validity check. For assessing the reliability of the checklist, inter-rater reliability was performed by two trained nurses of the ICU with the same professional characteristics and identical conditions. Kappa coefficient between the raters was obtained 1.0, which showed the very good agreement of ratings.

The data collection of this study was performed in the morning, afternoon, and night shifts in 3 consecutive days using the checklist. All evaluations and data collections were done by three masked ICU nurses, with the same expertise and experience in each shift, before the intervention in each day based on medical documents of the patients, observations, as well as the reports of the patients' nursing staff.

\section{Intervention}

In the control group, the patients were managed by administering antibiotics, vasoactive drugs, and mechanical ventilation, and were fed based on the routine procedure of the recruitment center (administration of additional fluids or electrolytes) according to medical indications. Type of feeding was the same for the both intervention groups. The patients in the both intervention groups received an already made complete diet (1 kcal/cc), through a gavage tube. The nutritional material (Karen Entera Meal powder, Tehran, Iran) was prescribed in seven measure cups mixed with 90 $\mathrm{cc}$ water to make $100 \mathrm{cc}$ of nutrition. The total number of calories and the required volume were calculated by a nutritionist and a critical care medicine fellowship through the Harris-Benedict equation, and the patients' condition.

In the both intervention groups, feeding was started after confirmation of NGT position and control of input and output. During feeding, all the patients had 30 degrees head up position. Also, the feeding solution was kept at room temperature for $30 \mathrm{~min}$ to be modified regarding its temperature before being gavaged. In both groups, EF was done based on DAA protocol. ${ }^{9}$ In the bolus feeding group, the needed calories were divided into six portions, and were gavaged within $15-20 \mathrm{~min}$ by a $50 \mathrm{cc}$ syringe (Asan Med, Tehran, Iran) sequentially three hourly for $18 \mathrm{~h}$ with night rest for $6 \mathrm{~h}$, and the volume of gavage increased by $50 \mathrm{cc}$ according to the patients' tolerance and GRV $(<200 \mathrm{cc})$ to achieve the targeted volume and calories. In the intermittent feeding group, feeding was administrated by a feeding pump (JMS pump, Tokyo, Japan) for $18 \mathrm{~h} /$ day with night rest for $6 \mathrm{~h}$. The gavage volume increased by $20-50$ cc every $4-6 \mathrm{~h}$ according to the patients' tolerance and GRV $(<200 \mathrm{cc})$ to reach the calculated calories and the volume for the patient.

In all three groups, the intervention was performed in three consecutive days by three ICU nurses with similar expertise and experience in each shift, which were unaware of the study details and aims. Also, all the patients were blind to the course of the intervention.

\section{Statistical Analysis}

Quantitative variables were shown as the mean and standard deviation of the mean, and qualitative variables were represented as a number of frequency and their percent. Kolmogorov-Smirnov test was used to examine the normal distribution of variables. To examine the differences in qualitative variables among the three groups, the researchers used Chi-square test and Fisher's exact tests. One-way analysis of variance (ANOVA) and Kruskal-Wallis test were used to detect the differences in 


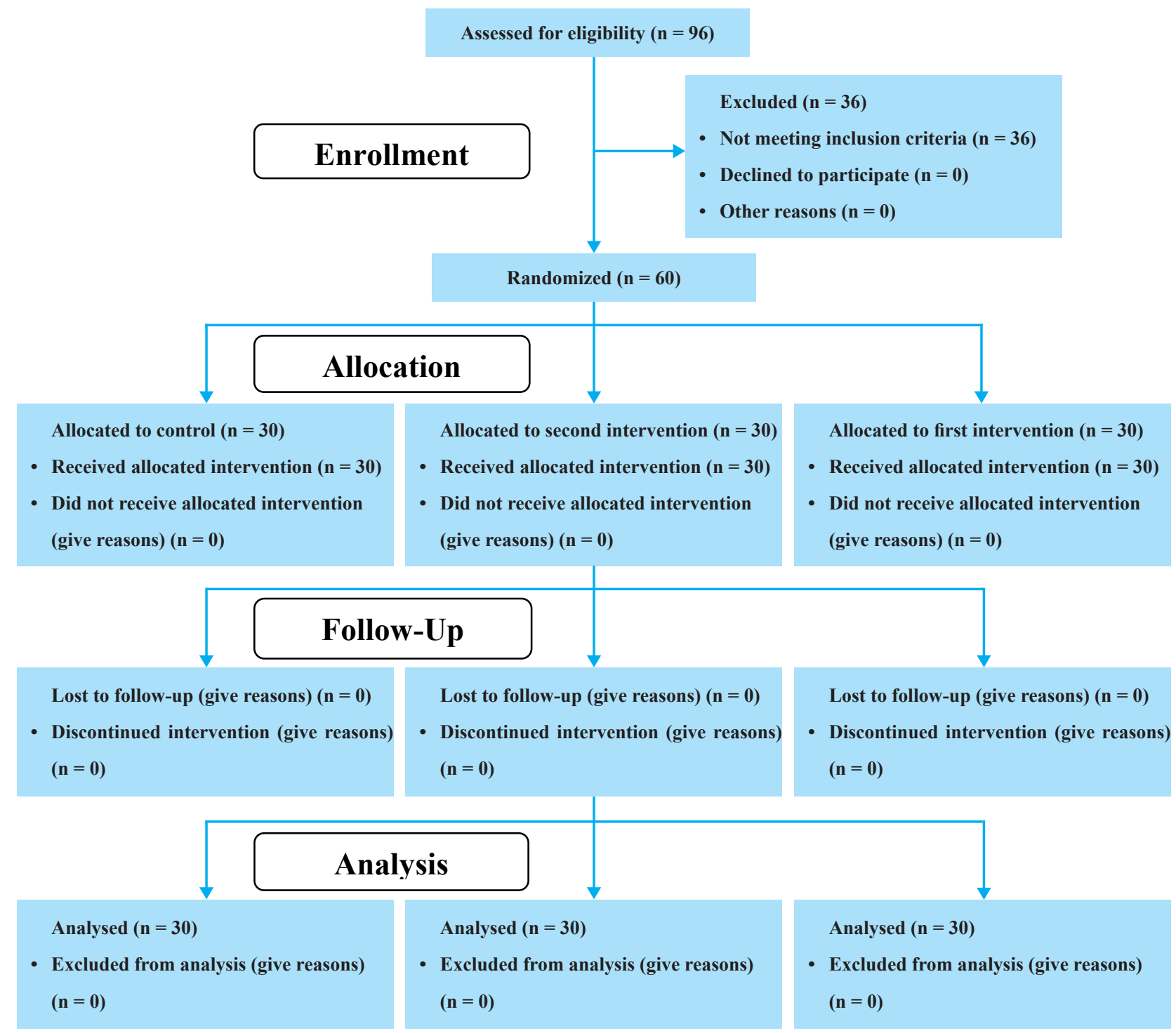

Fig.1: CONSORT flow diagram of the participants

quantitative variables between the groups. Friedman test and Cochran test were used to compare variables in each group during different times. All statistical analyses were done by SPSS software version 22 (SPSS, Inc. Chicago, IL, USA). $p$ values $<0.05$ was considered as statistically significant. The statistical analyzer was blinded to the codes.

\section{RESULTS}

\section{Follow up}

Of 96 patients assessed for eligibility in the study, 36 did not meet the inclusion criteria (score of the level of consciousness more than $10[\mathrm{n}=13]$, presence of obstruction or surgery of gastrointestinal system $[\mathrm{n}=8]$, and unhealthy digestive system $[n=15]) .60$ other patients were randomly allocated to three equal groups. All participants completed the study and were considered for final analysis (figure 1).

\section{General and clinical characteristics}

Characteristics of the patients in the three groups are presented in table 1 . There were no significant differences in age, sex, weight, and duration of hospital admissions among the three groups $(p>0.05)$. 
Table 1: Comparison of general and clinical characteristics of the patients between the three studied groups

\begin{tabular}{|c|c|c|c|c|c|c|}
\hline Variables & & $\begin{array}{l}\text { Bolus feeding } \\
\quad(\mathbf{n}=\mathbf{2 0})\end{array}$ & $\begin{array}{l}\text { Intermittent feeding } \\
\quad(\mathrm{n}=\mathbf{2 0})\end{array}$ & $\begin{array}{l}\text { Control } \\
(\mathrm{n}=\mathbf{2 0})\end{array}$ & Test results & $p$-value \\
\hline Age (year) & & $48.25 \pm 12.70$ & $54.60 \pm 14.16$ & $53.00 \pm 11.75$ & $\begin{array}{c}\text { Value }=1.309^{\dagger} \\
\text { df }=2\end{array}$ & 0.278 \\
\hline \multirow[t]{2}{*}{ Sex } & Male & $9(26.5)$ & $13(38.2)$ & $12(35.3)$ & \multirow{2}{*}{$\begin{array}{l}\text { Value }=1.765^{\dagger \dagger} \\
\quad d f=2\end{array}$} & \multirow{2}{*}{0.414} \\
\hline & Female & $11(42.3)$ & $7(26.9)$ & $8(30.8)$ & & \\
\hline Weight (Kg) & & $65.25 \pm 13.89$ & $65.80 \pm 7.88$ & $73.25 \pm 13.71$ & $\begin{array}{c}\text { Value }=2.704^{\dagger} \\
d f=2\end{array}$ & 0.075 \\
\hline \multicolumn{2}{|c|}{ Duration of hospital admissions (day) } & $6.30 \pm 4.24$ & $16.35 \pm 18.35$ & $10.80 \pm 8.52$ & $\begin{array}{c}\text { Value }=2.597^{\dagger \dagger \dagger} \\
\text { df }=2\end{array}$ & 0.273 \\
\hline
\end{tabular}

All values are expressed as mean $\pm \mathrm{SD}$ or number (percent)

$\dagger$ One way analysis of variance (ANOVA)

$\dagger$ Chi-square test

$\dagger$ Kruskal-Wallis test

\section{Gastrointestinal feeding intolerance}

Results showed no significant differences between the three studied groups in three intervention days regarding the frequency of constipation, diarrhea, vomiting, abdominal distention, and GRV (table 2). In none of the intervention days, there was no significant difference between the mean ranks of the studied groups in all variables (table 3). Also in total three intervention days, no significant difference was seen between the three groups in mean ranks of all variables (table 4). Friedman test showed no significant difference between the mean ranks of all variables in the three studied groups (table 5). Also in the three groups, the results of within groups by Cochran test showed no significant difference between the mean ranks of all variables.

\section{DISCUSSION}

In the present study, between groups results showed no significant differences in none of the three groups regarding all EF intolerance variables including constipation, diarrhea, vomiting, abdominal distention, and GRV. On the other hand, results indicated that all variables were not affected by the EF methods, probably because of precise technique, meticulous monitoring, and strict inclusion and exclusion criteria.

To the best of our knowledge, the present study is the first triple-blind controlled trial to compare EF intolerance of intermittent and bolus methods among critically ill patients with sepsis. The study included a prospective design, verifiable outcomes, standardized data collection methods, and capture of $100 \%$ of available patients in the ICU. In the present trial, strict criteria were considered to the selection of population to minimize any bias related to associated diseases and organ failures. Also, EF methods were well standardized and were according to the DAA protocol for EF.

We are aware of no other studies that compared EF intolerance of intermittent and bolus methods among critically ill patients with sepsis. Most previous studies have compared EF intolerance of other methods of feeding among patients with different critical illnesses. ${ }^{10-16}$ In this study, we did intermittent feeding using pump based on the DAA protocol for EF. Our findings expand the results of other investigations, which compared pump-assisted feeding to syringe-assisted feeding to assess EF intolerance of critically ill patients. In a trial by Zeraatkari and colleagues the incidence of diarrhea, nausea, and vomiting as indicators of EF intolerance did not have any significant difference in bolus, intermittent (using gravity drip), and pump-assisted continuous feeding methods among surgical ICU patients, although continuous method was better tolerated than both bolus and intermittent methods. ${ }^{23}$ In an observational prospective randomized clinical study by Tavares de Araujo and co-workers, which was done on hospital inpatients admitted to ICU, intermittent feeding using an infusion pump (during 18 hours with a 6-hour nocturnal pause) in comparison with continuous feeding indicated no statistically significant difference in vomiting, abdominal distension, or diarrhea. ${ }^{15}$ In a trial conducted in trauma ICU by MacLeod and colleagues there were no statistical differences in diarrhea and high GRV between the patients intermittently fed using gravity drip and those fed continuously. ${ }^{14}$ In another trial by Chen and others on critically ill patients under- 
Table 2: Comparison of the frequency of gastrointestinal feeding intolerance of the patients between the three studied groups in three intervention days

\begin{tabular}{|c|c|c|c|c|c|c|c|}
\hline Variables & Day & Time & $\begin{array}{l}\text { Bolus feeding } \\
\quad(n=20)\end{array}$ & $\begin{array}{l}\text { Intermittent feeding } \\
\qquad(\mathrm{n}=\mathbf{2 0})\end{array}$ & $\begin{array}{l}\text { Control } \\
(n=20)\end{array}$ & Test results & $p$-value \\
\hline \multirow{10}{*}{$\begin{array}{l}\text { Presence of } \\
\text { diarrhea }\end{array}$} & \multirow[t]{3}{*}{ First } & 0 & $19(34.5)$ & $20(36.4)$ & $16(29.1)$ & \multirow{3}{*}{ Value $=5.151^{\dagger}$} & \multirow{3}{*}{0.115} \\
\hline & & 1 & $1(25.0)$ & $0(0)$ & $3(75.0)$ & & \\
\hline & & 2 & $0(0)$ & $0(0)$ & $1(100)$ & & \\
\hline & \multirow[t]{4}{*}{ Second } & 0 & $16(34.5)$ & $18(35.30)$ & $17(33.3)$ & \multirow{4}{*}{ Value $=4.167^{\dagger}$} & \multirow{4}{*}{0.925} \\
\hline & & 1 & $2(28.6)$ & $2(28.60)$ & $3(42.9)$ & & \\
\hline & & 2 & $1(100)$ & $0(0)$ & $0(0)$ & & \\
\hline & & 3 & $1(100)$ & $0(0)$ & $0(0)$ & & \\
\hline & \multirow[t]{3}{*}{ Third } & 0 & $17(34.0)$ & $18(36.0)$ & $15(30.0)$ & \multirow{3}{*}{ Value $=3.841^{\dagger}$} & \multirow{3}{*}{0.474} \\
\hline & & 1 & $2(22.2)$ & $2(22.2)$ & $5(55.6)$ & & \\
\hline & & 2 & $1(100)$ & $0(0)$ & $0(0)$ & & \\
\hline \multirow{7}{*}{$\begin{array}{l}\text { Presence of } \\
\text { constipation }\end{array}$} & \multirow[t]{2}{*}{ First } & 0 & $19(32.2)$ & $20(33.9)$ & $20(33.9)$ & \multirow{2}{*}{ Value $=1.851^{\dagger}$} & \multirow{2}{*}{1.000} \\
\hline & & 2 & $1(100)$ & $0(0)$ & $0(0)$ & & \\
\hline & \multirow[t]{3}{*}{ Second } & 0 & $19(32.8)$ & $20(34.50)$ & $19(32.8)$ & \multirow{3}{*}{ Value $=3.669^{\dagger}$} & \multirow{3}{*}{1.000} \\
\hline & & 1 & $1(100)$ & $0(0)$ & $0(0)$ & & \\
\hline & & 2 & $0(100)$ & $0(0)$ & $1(100)$ & & \\
\hline & \multirow[t]{2}{*}{ Third } & 0 & $19(32.2)$ & $20(33.9)$ & $20(33.9)$ & \multirow{2}{*}{ Value $=1.851^{\dagger}$} & \multirow{2}{*}{1.000} \\
\hline & & 1 & $1(100)$ & $0(0)$ & $0(0)$ & & \\
\hline \multirow{6}{*}{$\begin{array}{l}\text { Presence of } \\
\text { vomiting }\end{array}$} & \multirow[t]{2}{*}{ First } & 0 & $19(32.8)$ & $19(32.8)$ & $20(34.5)$ & \multirow{2}{*}{ Value $=5.276^{\dagger}$} & \multirow{2}{*}{1.000} \\
\hline & & 1 & $1(50.0)$ & $1(50.0)$ & $0(0)$ & & \\
\hline & Second & 0 & $20(33.9)$ & $19(32.2)$ & $20(33.9)$ & Shl $-1051^{\dagger}$ & 1000 \\
\hline & & 1 & $0(0)$ & $1(100)$ & $0(0)$ & value -1.001 & 1.000 \\
\hline & Third & 0 & $19(32.2)$ & $20(33.9)$ & $20(33.9)$ & Y $1051^{\dagger}$ & 1000 \\
\hline & & 1 & $1(100)$ & $0(32.2)$ & $0(0)$ & value $=1.851$ & 1.000 \\
\hline & First & 0 & $16(30.2)$ & $19(35.8)$ & $18(34.0)$ & & \\
\hline & & 1 & $0(0)$ & $1(50.0)$ & $1(50.2)$ & 7611 & 0163 \\
\hline & & 2 & $3(100)$ & $0(0)$ & $0(0)$ & .101 & 0.105 \\
\hline & & 3 & $1(50)$ & $0(0)$ & $1(50.0)$ & & \\
\hline Presence of & Second & 0 & $17(32.7)$ & $18(34.6)$ & $17(32.7)$ & & \\
\hline distention & & 1 & $1(33.3)$ & $0(0)$ & $2(66.7)$ & Value $=2.443^{\dagger}$ & 0.848 \\
\hline & & 2 & $2(40.0)$ & $2(40.0)$ & $1(20.0)$ & & \\
\hline & Third & 0 & $19(33.3)$ & $19(33.3)$ & $19(33.3)$ & & \\
\hline & & 1 & $0(0)$ & $1(50.0)$ & $1(50.0)$ & Value $=3.060^{\dagger}$ & 1.000 \\
\hline & & 3 & $1(100)$ & $0(0)$ & $0(0)$ & & \\
\hline & First & 0 & $17(31.5)$ & $20(37.0)$ & $17(31.5)$ & & \\
\hline & & 1 & $2(40.0)$ & $0(0)$ & $3(60.0)$ & Value $=4.921^{\dagger}$ & 0.266 \\
\hline & & 2 & $1(100)$ & $0(0)$ & $0(0)$ & & \\
\hline Abnormal & Second & 0 & $19(35.8)$ & $19(35.8)$ & $15(28.3)$ & Value $=4.239^{\dagger \dagger}$ & 0107 \\
\hline volume* & & 1 & $1(14.3)$ & $1(14.3)$ & $5(71.4)$ & $\mathrm{df}=2$ & 0.192 \\
\hline & Third & 0 & $19(33.9)$ & $19(33.9)$ & $19(33.9)$ & & \\
\hline & & 1 & $1(33.3)$ & $1(33.3)$ & $1(33.3)$ & Value $=2.258^{\dagger}$ & 1.000 \\
\hline & & 3 & $0(0)$ & $0(0)$ & $0(0)$ & & \\
\hline
\end{tabular}

All values are expressed as number (percent)

* More than half of the previous aspirated feed or $200 \mathrm{cc}$

$\dagger$ Fisher Exact test

$\dagger$ Chi-square test 
Table 3: Comparison of the mean ranks of gastrointestinal feeding intolerance of the patients between the three studied groups in three intervention days

\begin{tabular}{|c|c|c|c|c|c|c|}
\hline Variables & Day & $\begin{array}{c}\text { Bolus feeding } \\
(\mathrm{n}=\mathbf{2 0})\end{array}$ & $\begin{array}{l}\text { Intermittent feeding } \\
\qquad(\mathbf{n}=\mathbf{2 0})\end{array}$ & $\begin{array}{l}\text { Control } \\
(\mathrm{n}=\mathbf{2 0})\end{array}$ & Test results $^{\dagger}$ & $p$-value \\
\hline \multirow{3}{*}{$\begin{array}{l}\text { Presence of } \\
\text { diarrhea }\end{array}$} & First & 29.48 & 28.00 & 34.03 & $\begin{array}{c}\text { Value }=5.636 \\
\mathrm{df}=2\end{array}$ & 0.060 \\
\hline & Second & 32.25 & 28.90 & 30.35 & $\begin{array}{c}\text { Value }=0.963 \\
\mathrm{df}=2\end{array}$ & 0.618 \\
\hline & Third & 30.18 & 28.45 & 32.88 & $\begin{array}{c}\text { Value }=1.561 \\
\mathrm{df}=2\end{array}$ & 0.458 \\
\hline \multirow{3}{*}{$\begin{array}{l}\text { Presence of } \\
\text { constipation }\end{array}$} & First & 31.50 & 30.00 & 30.00 & $\begin{array}{c}\text { Value }=2.000 \\
\mathrm{df}=2\end{array}$ & 0.368 \\
\hline & Second & 30.98 & 29.50 & 31.03 & $\begin{array}{c}\text { Value }=0.601 \\
\mathrm{df}=2\end{array}$ & 1.018 \\
\hline & Third & 31.50 & 30.00 & 30.00 & $\begin{array}{c}\text { Value }=2.000 \\
\mathrm{df}=2\end{array}$ & 0.368 \\
\hline \multirow{3}{*}{$\begin{array}{l}\text { Presence of } \\
\text { vomiting }\end{array}$} & First & 31.00 & 31.00 & 29.50 & $\begin{array}{c}\text { Value }=1.017 \\
\mathrm{df}=2\end{array}$ & 0.601 \\
\hline & Second & 30.00 & 31.50 & 30.00 & $\begin{array}{c}\text { Value }=2.000 \\
\mathrm{df}=2\end{array}$ & 0.368 \\
\hline & Third & 31.50 & 30.00 & 30.00 & $\begin{array}{c}\text { Value }=2.000 \\
\mathrm{df}=2\end{array}$ & 0.368 \\
\hline \multirow{3}{*}{$\begin{array}{l}\text { Presence of } \\
\text { abdominal } \\
\text { distention }\end{array}$} & First & 33.13 & 28.36 & 30.00 & $\begin{array}{c}\text { Value }=2.461 \\
\mathrm{df}=2\end{array}$ & 0.293 \\
\hline & Second & 31.03 & 29.65 & 30.83 & $\begin{array}{c}\text { Value }=0.208 \\
\mathrm{df}=2\end{array}$ & 0.901 \\
\hline & Third & 30.55 & 30.48 & 30.48 & $\begin{array}{c}\text { Value }=0.002 \\
\mathrm{df}=2\end{array}$ & 0.999 \\
\hline \multirow{3}{*}{$\begin{array}{l}\text { Abnormal } \\
\text { gastric residual } \\
\text { volume** }\end{array}$} & First & 32.08 & 27.50 & 31.93 & $\begin{array}{c}\text { Value }=3.275 \\
\mathrm{df}=2\end{array}$ & 0.194 \\
\hline & Second & 28.50 & 28.50 & 34.50 & $\begin{array}{c}\text { Value }=5.089 \\
\mathrm{df}=2\end{array}$ & 0.079 \\
\hline & Third & 31.55 & 29.98 & 29.98 & $\begin{array}{c}\text { Value }=0.580 \\
\mathrm{df}=2\end{array}$ & 0.748 \\
\hline
\end{tabular}

All values are expressed as mean ranks

$*$ More than half of the previous aspirated feed or $200 \mathrm{cc}$

$\dagger$ Kruskal-Wallis test

Table 4: Comparison of the mean ranks of gastrointestinal feeding intolerance of the patients between the three studied groups in total three intervention days

\begin{tabular}{|c|c|c|c|c|c|}
\hline Variables & $\begin{array}{l}\text { Bolus feeding } \\
\quad(n=20)\end{array}$ & $\begin{array}{l}\text { Intermittent feeding } \\
\qquad(\mathrm{n}=20)\end{array}$ & $\begin{array}{l}\text { Control } \\
(n=20)\end{array}$ & Test results ${ }^{\dagger}$ & $p$-value \\
\hline Presence of diarrhea & 30.65 & 25.70 & 35.15 & $\begin{array}{c}\text { Value }=4.846 \\
\text { df }=2\end{array}$ & 0.088 \\
\hline Presence of constipation & 32.00 & 29.00 & 30.50 & $\begin{array}{c}\text { Value }=2.070 \\
\mathrm{df}=2\end{array}$ & 0.355 \\
\hline Presence of vomiting & 31.95 & 30.55 & 29.00 & $\begin{array}{c}\text { Value }=2.002 \\
\mathrm{df}=2\end{array}$ & 0.367 \\
\hline Presence of abdominal distention & 32.48 & 28.75 & 30.28 & $\begin{array}{c}\text { Value }=0.944 \\
\text { df }=2\end{array}$ & 0.624 \\
\hline Abnormal gastric residual volume* & 31.13 & 26.10 & 33.28 & $\begin{array}{c}\text { Value }=4.003 \\
\text { df }=2\end{array}$ & 0.135 \\
\hline
\end{tabular}

All values are expressed as mean ranks

* More than half of the previous aspirated feed or $200 \mathrm{cc}$

$\dagger$ Kruskal-Wallis test 
Table 5: Comparison of the mean ranks of gastrointestinal feeding intolerance of the patients within the three studied groups in three intervention days

\begin{tabular}{|c|c|c|c|c|c|c|}
\hline Variables & Groups & First & Second & Third & Test results $^{\dagger}$ & $p$-value \\
\hline \multirow{3}{*}{$\begin{array}{l}\text { Presence of } \\
\text { diarrhea }\end{array}$} & Bolus feeding & 1.85 & 2.13 & 2.03 & $\begin{array}{c}\text { Value }=3.647 \\
\mathrm{df}=2\end{array}$ & 0.161 \\
\hline & $\begin{array}{l}\text { Intermittent } \\
\text { feeding }\end{array}$ & 1.90 & 2.05 & 2.05 & $\begin{array}{c}\text { Value }=4.000 \\
d f=2\end{array}$ & 0.135 \\
\hline & Control & 2.00 & 1.93 & 2.08 & $\begin{array}{c}\text { Value }=0.667 \\
d f=2\end{array}$ & 0.717 \\
\hline \multirow{3}{*}{$\begin{array}{l}\text { Presence of } \\
\text { constipation }\end{array}$} & Bolus feeding & 2.00 & 2.00 & 2.00 & $\begin{array}{c}\text { Value }=0.000 \\
\text { df }=2\end{array}$ & 1.000 \\
\hline & $\begin{array}{l}\text { Intermittent } \\
\text { feeding }\end{array}$ & 2.00 & 2.00 & 2.00 & $\begin{array}{c}\text { Value }=0.000 \\
\quad d f=2\end{array}$ & 1.000 \\
\hline & Control & 1.98 & 2.05 & 1.98 & $\begin{array}{c}\text { Value }=2.000 \\
d f=2\end{array}$ & 0.368 \\
\hline \multirow{3}{*}{$\begin{array}{l}\text { Presence of } \\
\text { vomiting }\end{array}$} & Bolus feeding & 2.03 & 1.95 & 2.03 & $\begin{array}{c}\text { Value }=1.000 \\
\mathrm{df}=2\end{array}$ & 0.607 \\
\hline & $\begin{array}{l}\text { Intermittent } \\
\text { feeding }\end{array}$ & 2.03 & 2.03 & 1.95 & $\begin{array}{c}\text { Value }=2.000 \\
d f=2\end{array}$ & \\
\hline & Control & 2.00 & 2.00 & 2.00 & $\begin{array}{c}\text { Value }=0.000 \\
d f=2\end{array}$ & 1.000 \\
\hline \multirow{3}{*}{$\begin{array}{l}\text { Presence of } \\
\text { abdominal } \\
\text { distention }\end{array}$} & Bolus feeding & 2.13 & 1.98 & 1.90 & $\begin{array}{c}\text { Value }=2.471 \\
d f=2\end{array}$ & 0.291 \\
\hline & $\begin{array}{l}\text { Intermittent } \\
\text { feeding }\end{array}$ & 1.98 & 2.08 & 1.95 & $\begin{array}{c}\text { Value }=1.400 \\
d f=2\end{array}$ & 0.497 \\
\hline & Control & 2.03 & 2.05 & 1.93 & $\begin{array}{c}\text { Value }=1.077 \\
d f=2\end{array}$ & 0.584 \\
\hline \multirow{3}{*}{$\begin{array}{l}\text { Abnormal } \\
\text { gastric residu- } \\
\text { al volume* }\end{array}$} & Bolus feeding & 2.08 & 1.93 & 2.00 & $\begin{array}{c}\text { Value }=1.200 \\
d f=2\end{array}$ & 0.549 \\
\hline & $\begin{array}{l}\text { Intermittent } \\
\text { feeding }\end{array}$ & 1.95 & 2.03 & 2.03 & $\begin{array}{c}\text { Value }=2.000 \\
d f=2\end{array}$ & 0.368 \\
\hline & Control & 2.00 & 2.15 & 1.85 & $\begin{array}{c}\text { Value }=4.000 \\
d f=2\end{array}$ & 0.135 \\
\hline
\end{tabular}

All values are expressed as mean ranks

* More than half of the previous aspirated feed or $200 \mathrm{cc}$

$\dagger$ Friedman test

going ventilators, the patients in the intermittent feeding group (using gravity drip every four hours) had a higher GRV than the patients in continuous feeding group, however, no significant differences were observed between the groups. ${ }^{16}$ Also, Serpa and colleagues in a prospective controlled study reported no significant differences between high GRV, abdominal distention, diarrhea, and vomiting in critically ill patients who received EF by bolus method ( 8 aliquots over a 1 -hour period each at intervals of 3 hours) and continuous method over a 3-day period. ${ }^{11}$ In another study conducted on critically ill mechanically ventilated patients by Kadamani and co-workers no statistically significant differences was reported between the pump-assisted continuous versus bolus groups on the occurrence of high GRV, diarrhea, and vomiting; however, constipation was significantly more in patients receiving continuous feeding (66.7\%) as compared with those receiving bolus feeding (20\%, $p=0.025) .{ }^{12}$ In other similar trial on healthy adult male volunteers, Chowdhury and colleagues reported that bolus feeding via syringe delivered over 5 minutes led to a significant increase in GRV compared with continuous feeding via pump delivered at $100 \mathrm{~mL} / \mathrm{h}$ over 4 hours $(p<0.0001)$, and there was a significant increase in diarrhea with bolus feeding after 90 minutes $(p<0.0068)$ while continuous feeding did not increase diarrhea.10 In another study by Hiebert and others in burn-injured patients, it was found that significantly 
less constipation observed in patients treated with continuous pump tube feeding over those fed intermittently $(p<0.0001) .{ }^{13}$ The differences may be due to different patients and intervention methods such as the use of feeding pump, the rate of feeding administration, diet, positioning and type of the tube, and monitoring of the patients.

Our study findings demonstrated that EF intolerance of patients with sepsis was similar by using both the bolus and intermittent feeding methods. Therefore, due to the expense of equipment in intermittent pump feeding, also easy usage of bolus method, it can be suggested that bolus feeding can still be used as a standard and proper method by nurses for substituting other feeding techniques in patients admitted to ICUs, however more related studies to determine the safest feeding method are needed.

\section{CONCLUSION}

Intermittent pump feeding did not significantly affect EF intolerance in tube-fed hospital inpatients with sepsis compared with bolus and routine methods.

\section{Limitations}

Some limitations of this study should be considered. Firstly, we observed EF intolerance in a 3-day periods. An assessment period longer than 3 days may fortify the differences between the methods; however, this is difficult in busy ICUs having short overall durations of hospital admissions. Secondly, this study was conducted on patients with sepsis and the findings could not be generalized to other patients. Thirdly, the sample size was small due to the large number of exclusion criteria characterized to reduce the confounding variables and the inability to select other centers with similar patients. So, further studies are recommended to perform in a multi-center design with a much larger sample size of the same patients, longer feeding periods, and dietetic prescriptions to advance the knowledge about these common EF techniques.

\section{ACKNOWLEDGEMENT}

We appreciate the Vice-chancellery for Research Affairs of AJA University of Medical Sciences for technical support as well as valuable assistance of all patients and their families. We also sincerely thank the chief of Shahid Chamran Hospital, Tehran, Iran, and staff of intensive care units of this hospital.

\section{Authors' contribution}

Nasiri M contributed to interpretation of data for the work, drafting the manuscript and revising it critically for important intellectual content. Farsi $\mathrm{Z}$ contributed to the concept and design, analysis and interpretation of data and drafting and critical revision of the manuscript. Ahangeri $M$ contributed to the concept and design, acquisition and analysis and drafting the manuscript. Dadgari $F$ contributed to the concept and design, and drafting the manuscript. All authors read and approved the final manuscript, and be accountable for all aspects of the work in ensuring that questions related to the accuracy or integrity of any part of the work are appropriately investigated and resolved.

\section{Funding source}

This work is the main part of MSc thesis of critical care nursing with grant NO. 594243, which was supported by AJA University of Medical Sciences, Tehran, Iran.

\section{Institutional Review Board}

Ethic Review Board of AJA University of Medical Sciences, Tehran, Iran, approved the study (code No. IR.AJAUMS.REC.38.1394).

Iranian Registry of Clinical Trials (IRCT) number (http://www.irct.ir/): IRCT2015102623446N2

\section{CONFLICT OF INTEREST}

The authors declare no conflict of interest related to this work.

\section{REFERENCES}

1. Hooper MH, Marik PE. Controversies and Misconceptions in Intensive Care Unit Nutrition. Clin Chest Med 2015;36:409-18. doi: 10.1016/j.ccm.2015.05.013.

2. Ridley E, Gantner D, Pellegrino V. Nutrition therapy in critically ill patients- a review of current evidence for clinicians. Clin Nutr 2015;34:565-71. doi: 10.1016/j. clnu.2014.12.008.

3. Flordelís Lasierra JL, Pérez-Vela JL, Montejo González JC. Enteral nutrition in the hemodynamically unstable critically ill patient. Med Intensiva 2015;39:40-8. doi: 10.1016/j.medin.2014.04.002. 
4. McClaveSA, Martindale RG, RiceTW, HeylandDK. Feeding the critically ill patient. Crit Care Med 2014;42:260010. doi: 10.1097/CCM.0000000000000654.

5. Madl C, Holzinger U. Nutrition and gastrointestinal intolerance. Med Klin Intensivmed Notfmed 2013;108:396400. doi: 10.1007/s00063-012-0203-1.

6. Blaser AR, Starkopf J, Kirsimägi Ü, Deane AM. Definition, prevalence, and outcome of feeding intolerance in intensive care: a systematic review and meta-analysis. Acta Anaesthesiol Scand 2014;58:914-22. doi: 10.1111/ aas. 12302 .

7. Gungabissoon U, Hacquoil K, Bains C, Irizarry M, Dukes G, Williamson R, et al. Prevalence, risk factors, clinical consequences, and treatment of enteral feed intolerance during critical illness. J Parenter Enteral Nutr 2015;39:441-8. doi: 10.1177/0148607114526450.

8. Mentec H, Dupont H, Bocchetti M, Cani P, Ponche F, Bleichner G. Upper digestive intolerance during enteral nutrition in critically ill patients: frequency, risk factors, and complications. Crit Care Med 2001;29:1955-61.

9. Ferrie S, Daniells S, Gagnon S, Hamlyn J, Jukkola K, Riley N, et al. Enteral nutrition manual for adults in health care facilities. Dietitians Association of Australia [Internet]. 2011 Oct [cited 2016 Feb]. Available from: http:// daa.asn.au/wp-content/uploads/2011/11/Enteral-nutrition-manual-Oct-2011.pdf.

10. Chowdhury AH, Murray K, Hoad CL, Costigan C, Marciani L, Macdonald IA, et al. Effects of Bolus and Continuous Nasogastric Feeding on Gastric Emptying, Small Bowel Water Content, Superior Mesenteric Artery Blood Flow, and Plasma Hormone Concentrations in Healthy Adults: A Randomized Crossover Study. Ann Surg 2016;263:450-7. doi: 10.1097/SLA.0000000000001110.

11. Serpa LF, Kimura M, Faintuch J, Ceconello I. Effects of continuous versus bolus infusion of enteral nutrition in critical patients. Rev Hosp Clin Fac Med Sao Paulo 2003;58:9-14

12. Kadamani I, Itani M, Zahran E, Taha N. Incidence of aspiration and gastrointestinal complications in critically ill patients using continuous versus bolus infusion of enteral nutrition: a pseudo-randomised controlled trial. Aust Crit Care 2014;27:188-93. doi: 10.1016/j.aucc.2013.12.001.

13. Hiebert JM, Brown A, Anderson RG, Halfacre S, Rodeheaver GT, Edlich RF. Comparison of continuous vs intermittent tube feedings in adult burn patients. $J$ Parenter Enteral Nutr 1981;5:73-5. doi:10.1177/01486071810050 0173.

14. MacLeod JB, Lefton J, Houghton D, Roland C, Doherty $\mathrm{J}$, Cohn SM, et al. Prospective randomized control trial of intermittent versus continuous gastric feeds for critically ill trauma patients. J Trauma 2007;63:57-61. doi: 10.1097/01.ta.0000249294.58703.11.

15. Tavares de Araujo VM, Gomes PC, Caporossi C. Enteral nutrition in critical patients; should the administration be continuous or intermittent? Nutr Hosp 2014;29:563-7. doi:10.3305/nh.2014.29.3.7169.

16. Chen YC, Chou SS, Lin LH, Wu LF. The effect of intermittent nasogastric feeding on preventing aspiration pneumonia in ventilated critically ill patients. J Nurs Res 2006;14:167-80.

17. Braun J, Bein T, Wiese CH, Graf BM, Zausig YA. Enteral feeding tubes for critically ill patients. Anaesthesist 2011;600:352-65. doi:10.1007/s00101-010-1800-0.

18. Heyland DK. Critical care nutrition support research: lessons learned from recent trials. Curr Opin Clin Nutr Metab Care 2013;16:176-81. doi: 10.1097/MCO.0b013e32835bdfaf.

19. Lavrentieva A, Kontakiotis T, Bitzani M. Enteral nutrition intolerance in critically ill septic burn patients. J Burn Care Res 2014;35:313-8. doi: 10.1097/ BCR.0b013e3182a22403.

20. Fremont RD, Rice TW. Pros and cons of feeding the septic intensive care unit patient. Nutr Clin Pract 2015;30:34450. doi:10.1177/0884533615578457.

21. Musazadeh S, Hasavari F, Kazemnejal Lili E, Anoush D, Khaleghdost T. Comparison of the incidence of pulmonary aspiration in two ways intermittent bolus feeding and intermittent drip bag. Crit Care Nurs 2012;5:1-11.

22. Elke G, Felbinger TW, Heyland DK. Gastric residual volume in critically ill patients: a dead marker or still alive? Nutr Clin Pract 2015;30:59-71. doi: $10.1177 / 0884533614562841$.

23. Zeraatkari KH, Soltani HA, Jaberi A, Eghbali M. Continuous method of enteral feeding was better tolerated in SICU patients than bolus method: A691. Eur J Anaesthesiol 2004;21:170. 